\title{
Estimation of Hot Torsion Stress Strain Curves in Iron Alloys Using a Neural Network Analysis
}

\author{
V. NARAYAN, R. ABAD, ${ }^{1)}$ B. LOPEZ,") H. K. D. H. BHADESHIA ${ }^{2)}$ and D. J. C. MACKAY2) \\ Department of Materials Science and Metallurgy, University of Cambridge, Pembroke Street, Cambridge CB2 302 , UK. \\ 1) Centro de Estudios e Investigaciones Tecnicas de Guipuzcoa, $P^{0}$ de Manuel de Lardizabal, $15, B^{\circ}$ Ibaeta, 20.009 San \\ Sebastian, Spain \\ 2) Mathematical and Physical Sciences Group, Darwin College, Silver Street, Cambridge CB3 9EU, UK.
}

(Received on August 31, 1998; accepted in final form on January 21, 1999)

\begin{abstract}
The hot torsion stress-strain curves of steels have been modelled using a neural network, within a Bayesian framework. The analysis is based on an extensive database consisting of detailed chemical composition, temperature and strain rate from new hot torsion experiments. Non-linear functions are obtained, describing the variation of stress-strain curves with temperature and chemical composition. Predictions are associated with error bars, whose magnitude depends on their position in the input space. From the population of possible models, a "committee of models" is found to give the most reliable estimate. The results from the neural network model where found to be consistent with known models, and reasonable estimates are obtained beyond the scope of the experimental data.
\end{abstract}

KEY WORDS: hot-deformation; torsion test; austenite; recrystallisation; hot-rolling; steel; neural network.

\section{Introduction}

There has been considerable interest in the behaviour of low-alloy steels when deformed to high strains at high temperatures. ${ }^{1)}$ This is because the vast majority of steels are processed by hot-rolling, under conditions in which the austenite is repeatedly recrystallised, ${ }^{2,3)}$ in order to refine the grain structure. ${ }^{4)}$ Dynamical recovery ${ }^{5,6)}$ and grain growth ${ }^{7)}$ may also occur. Models of the hot working process rely on a representation of the stress versus plastic strain curve of the austenite. The purpose of the present work was to see whether measured stress-strain curves can be adequately represented using neural network analysis, a technique which has been demonstrated to be extremely useful in dealing with complex metallurgical problems.

There is a large amount of high temperature stressstrain torsion measurements available in the literature. ${ }^{8)}$ It is well known that recrystallisation is a complicated process, highly dependent on temperature and strain rate $^{9,10)}$ It is not surprising therefore, that an examination of the torsion data reveals that a linear relationship between the plastic limit and the solute concentration, temperature or strain rate is not necessarily valid. Linear regression techniques thus, are not appropriate. We shall use instead, a neural network ${ }^{11,12)}$ to model the dependence of the stress on strain as a function of many variables ${ }^{13)}$ which include the chemical composition and temperature. A neural network is capable of modelling highly non-linear relations. In addition, the model allows the estimation of error bars whose magnitude depends upon the position in the input space and the preceived level of noise in the experimental data. The neural network analysis can be considered to be a more general form of existing empirical models. ${ }^{14,15)}$

\section{The Database}

The torsion measurements were performed on the fifteen different steels whose chemical compositions are listed in Table 1; with the exception of $\mathrm{H} 04$, they are all microalloyed, either with vanadium or niobium. Most alloys were electric arc melted and made into 0.5 ton ingots. Cylindrical samples were extracted from areas parallel to the ingot axis and adjacent to the ingot surface. Furthermore, blast furnace and continuous casting technologies have been used to produce additional samples. These samples may have two geometries: diameter of $7.5 \mathrm{~mm}$ and length $17 \mathrm{~mm}$, or diameter $6 \mathrm{~mm}$ and length $13 \mathrm{~mm}$. Following austensization at $1200^{\circ} \mathrm{C}$ for $15 \mathrm{~min}$ in a radiant furnace, the samples were tested in a purified argon atmosphere for at least fourteen different temperatures in the range $1200-700^{\circ} \mathrm{C}$. Prior to each test, the samples were allowed to stabilise for 5-100 s. A computer control system is used to record the twist and torque data, which were converted into shear-stress through the Fields and Backofen technique and then transformed to equivalent stress and strain using the von Mises criterion. ${ }^{16,17)}$

\section{The Neural Network Model}

The neural network inputs include temperatures, 
Table 1. The chemical compositions of the alloys examined by hot torsion stress-strain measurements.

\begin{tabular}{|c|c|c|c|c|c|c|c|c|}
\hline \multirow{2}{*}{ Alloy } & \multicolumn{8}{|c|}{ Composition $(\% \mathrm{wt})$ bal $\mathrm{Fe}$} \\
\hline & $\mathrm{C}$ & $\mathrm{Si}$ & $\mathrm{Mn}$ & $\mathrm{Cr}$ & $\mathrm{Ni}$ & $\mathrm{Nb}$ & V & $\mathrm{Ti}$ \\
\hline H05 & 0.082 & 0.36 & 1.47 & 0.02 & 0.03 & 0.051 & 0.08 & 0.0 \\
\hline BSI & 0.1 & 0.31 & 1.42 & 0.02 & 0.02 & 0.035 & 0.0 & 0.0 \\
\hline $\mathrm{H} 04$ & 0.14 & 0.02 & 1.18 & 0.02 & 0.08 & 0.0 & 0.0 & 0.0 \\
\hline $\mathrm{Nb}$ & 0.11 & 0.51 & 1.14 & 0.0 & 0.029 & 0.049 & 0.0 & 0.0 \\
\hline H 22038 & 0.07 & 0.012 & 0.62 & 0.019 & 0.024 & 0.034 & 0.0 & 0.067 \\
\hline 2077 & 0.37 & 0.56 & 1.45 & 0.04 & 0.07 & 0.0 & 0.11 & 0.0 \\
\hline V-GSB & 0.455 & 0.74 & 1.55 & 0.26 & 0.08 & 0.0 & 0.12 & 0.007 \\
\hline $4 \mathrm{~A}$ & 0.036 & 0.02 & 1.5 & 0.0 & 0.0 & 0.078 & 0.0 & 0.0 \\
\hline $4 \mathrm{~B}$ & 0.047 & 0.02 & 1.38 & 0.0 & 0.0 & 0.061 & 0.0 & 0.03 \\
\hline $6 \mathrm{~A}$ & 0.044 & 0.02 & 1.39 & 0.0 & 0.0 & 0.062 & 0.0 & 0.066 \\
\hline $6 \mathrm{~B}$ & 0.044 & 0.02 & 1.35 & 0.0 & 0.0 & 0.064 & 0.0 & 0.029 \\
\hline $7 \mathrm{~B}$ & 0.06 & 0.02 & 1.47 & 0.0 & 0.0 & 0.06 & 0.0 & 0.025 \\
\hline $\mathrm{H} 63$ & 0.07 & 0.165 & 1.51 & 0.0 & 0.0 & 0.048 & 0.019 & 0.129 \\
\hline K63 & 0.072 & 0.21 & 0.958 & 0.0 & 0.0 & 0.046 & 0.0 & 0.011 \\
\hline 7481 & 0.373 & 0.6 & 1.4 & 0.07 & 0.07 & 0.0 & 0.11 & 0.015 \\
\hline
\end{tabular}

Table 2. The variables used in the neural network analysis.

\begin{tabular}{llll}
\hline \multicolumn{1}{c}{ Variables } & \multicolumn{1}{c}{ Range } & Mean & $\begin{array}{l}\text { Standard } \\
\text { deviation }\end{array}$ \\
\hline Temperature $\left({ }^{\circ} \mathrm{C}\right)$ & $676-1181$ & 953.1 & 134.7 \\
Strain rate $\left(\mathrm{s}^{-1}\right)$ & $0.25-1.8$ & 1.309 & 0.4759 \\
Interpass time $(\mathrm{s})$ & $0-100$ & 39.6 & 30.0 \\
$\mathrm{C}(\% \mathrm{wt})$ & $0.036-0.455$ & 0.1254 & 0.1298 \\
$\mathrm{Si}(\% \mathrm{wt})$ & $0.012-0.74$ & 0.1873 & 0.2414 \\
$\mathrm{Mn}(\% \mathrm{wt})$ & $0.62-1.55$ & 1.281 & 0.295 \\
$\mathrm{Cr}(\% \mathrm{wt})$ & $0.0-0.26$ & 0.02469 & 0.057 \\
$\mathrm{Ni}(\% \mathrm{wt})$ & $0.0-0.08$ & 0.01944 & 0.02717 \\
$\mathrm{Nb}(\% \mathrm{wt})$ & $0.0-0.078$ & 0.0423 & 0.02386 \\
$\mathrm{~V}(\% \mathrm{wt})$ & $0.0-0.12$ & 0.02454 & 0.0444 \\
$\mathrm{Ti}$ & $0.0-0.129$ & 0.0379 & 0.0324 \\
$\mathrm{Strain}$ & $0.0406-0.8422$ & 0.1643 & 0.1275 \\
log(Stress) & $0.2953-0.5759$ & 0.4694 & 0.5214 \\
Measurement & $0.0-0.8422$ & 0.3 & 0.1677 \\
$\quad$ & & & \\
\hline
\end{tabular}

interpass time, strain rate, chemical composition, the measured $\log$ of the equivalent stress being the output. The range, mean and standard deviation of the input and output data are listed in Table 2. Torsion tests are frequently conducted in several stages, in order to simulate passes in a rolling mill. The total plastic strain in the previous pass therefore, can matter in determining the deformation characteristics of the current test. This has been taken into account by including a "measurement history", which is the largest strain value, of the previous stress-strain measurement. Each of the variables was normalised within the range \pm 0.5 :

$$
x_{N}=\frac{x-x_{\min }}{x_{\max }-x_{\min }}-0.5
$$

where $x_{N}$ is the normalised value of $x, x_{\max }$ is the maximum value and $x_{\min }$ is the minimum value. This normalisation permits comparison of the relative importance of individual inputs in the analysis.

The structure of the neural network model is shown in Fig. 1. The inputs and outputs are connected through

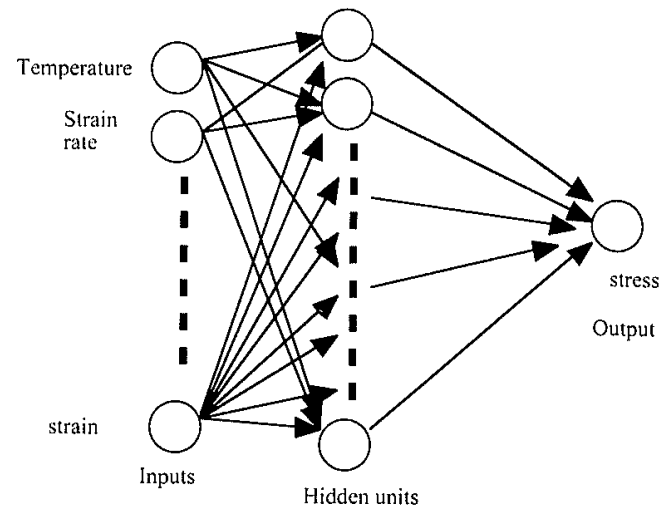

Fig. 1. The neural network structure.

hidden units $h_{i}$ where the inputs $x_{j}$ are operated by a hyperbolic tangent transfer function:

$$
h_{i}=\tanh \left(\sum_{j} w_{i j}^{(1)} x_{j}+\theta_{i j}^{(1)}\right)
$$

were $\theta_{i}^{(1)}$ is defined as the bias (analogous to the constant that appears in the linear regression method), $w_{i, j}$ are defined as the weights that determine the strength of the transfer function. All the hidden units contribute to the output as follows:

$$
y=\sum_{i} w_{i}^{(2)} h_{i}+\theta^{(2)}
$$

were $w_{i}^{(2)}$ and $\theta^{(2)}$ are a second set of weights and a bias. Equations (2) and (3) completely define the neural network structure that connects the inputs to the output. The weights and biases however, are unknowns to be determined through "training" using the Bayesian back propagation scheme, which involves a minimisation of the function:

$$
M(w)=\beta E_{D}+\sum_{c} \alpha_{c} E_{w(c)}
$$

where $E_{D}$ is defined as:

$$
E_{D}(\mathbf{w})=\frac{1}{2} \sum_{m} \sum_{i}\left(y_{i}\left(\mathbf{x}^{m}, \mathbf{w}\right)-t^{m}\right)^{2}
$$

where the data set $\left\{x^{m}, t^{m}\right\}$ consists of $x^{m}$ inputs related to a particular target $t^{m}$ ( $m$ labels the set of inputs to output mappings). The parameter $\beta$ therefore, defines the noise level $\sigma_{v}^{2}=1 / \beta$. The aim is to determine a set of weights in a manner that minimises $E_{D}$ but without overfitting to noise. Thus, the regularisers $E_{w}$ are included so that smooth solutions of $y\left(\mathbf{x}^{m}, \mathbf{w}\right)$ are favoured and fitting to noise in the experimental data can be minimised. The parameter $\alpha$ thus defines the "significance" $\sigma_{w}^{2}=1 / \alpha$ of a particular input. Large values of $\sigma_{w}^{2}$, i.e. small values of $\alpha$, correspond to a greater significance for a particular input since the weights for that input are penalised to a smaller extent. We use the automatic relevance determination model ${ }^{18)}$ as described in the literature instead of the simplest regulariser, that has the form $E_{w}=$ $(1 / 2) \sum w_{i}^{2}$. For "training", we must first randomise the database and then divide it into two equal parts. The first half of this database (the "training" data), is used to determine the weights and biases for each model. 


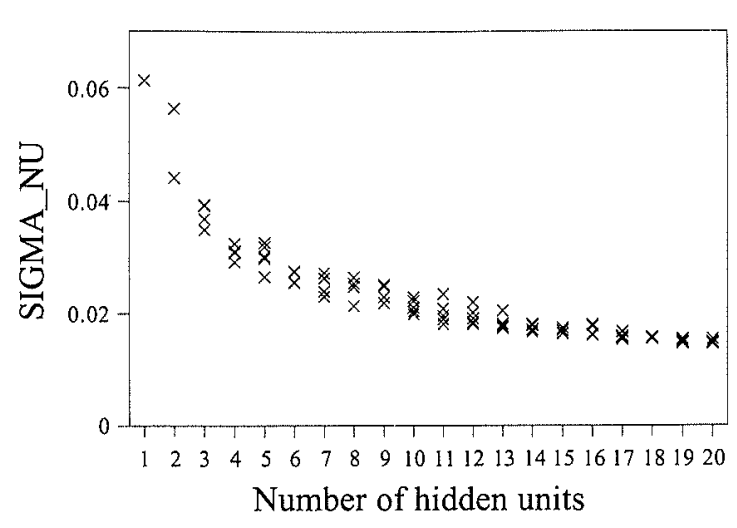

Fig. 2. The variation in $\sigma$, for the stress of as a function of hidden units shown for five different seed values for each network.

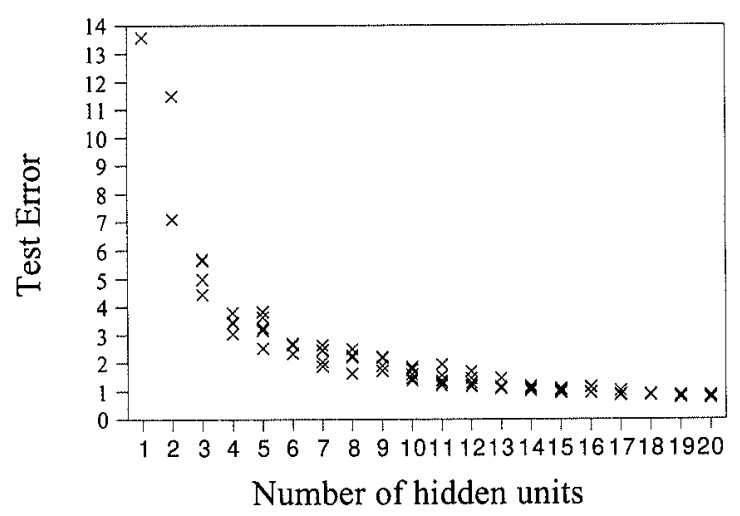

Fig. 3. The test error as a function of hidden units for five different seed values.

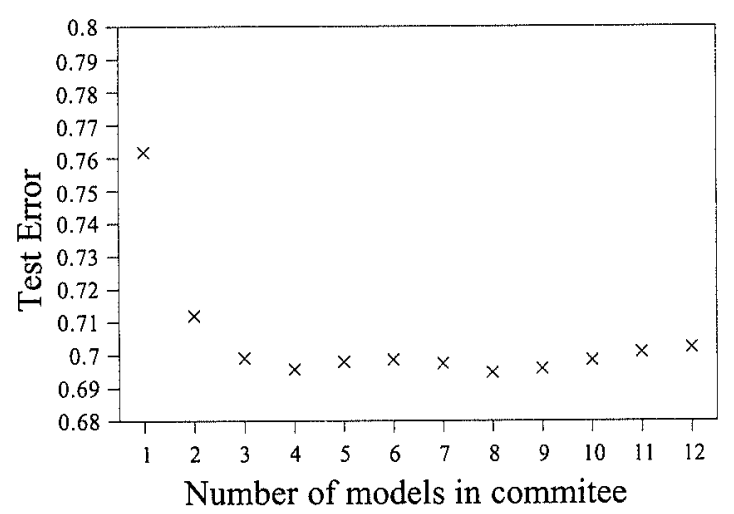

Fig. 4. The change in the test error with the number of models used in the committee.

The number of hidden units used determines the complexity. The value of $\sigma_{v}$, the model perceived noise in the data, therefore decreases monotonically with the number of hidden units, as shown in Fig. 2. The test error, defined as the value of the error function for unseen data is shown in Fig. 3. The choice of a model with a minimum test error avoids the problem of overfitting. The best model can be chosen as that with the smallest test error. However we choose the best model according to a quantity the "log predictive error" (LPE), because unlike the test error, the LPE put less emphasis on any outliers if those outliers are accompanied by appropriately large error bars. The LPE, assuming that the neural network gives a prediction Normal $\left(y^{m}, \sigma_{y}^{m^{2}}\right)$ where $\sigma_{y}^{m^{2}}$ is an error bar calculated using bayesian statistics, has
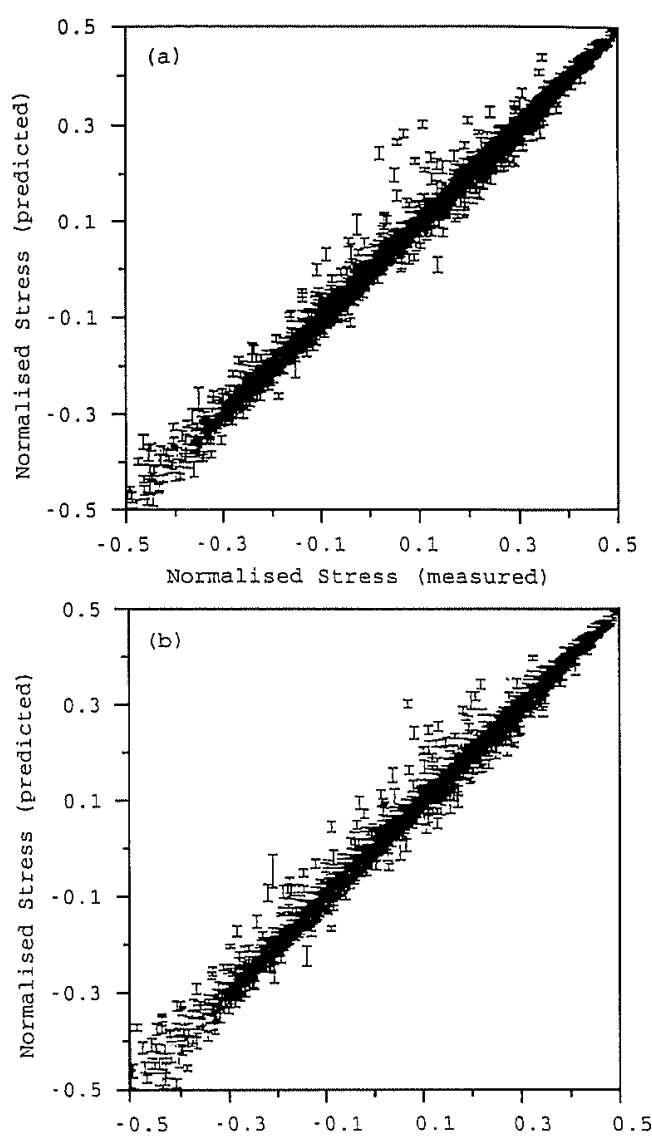

Fig. 5. The comparison of the measured stress with the neural network committee prediction for the (a) "training data" and (b) the unseen "test" data.

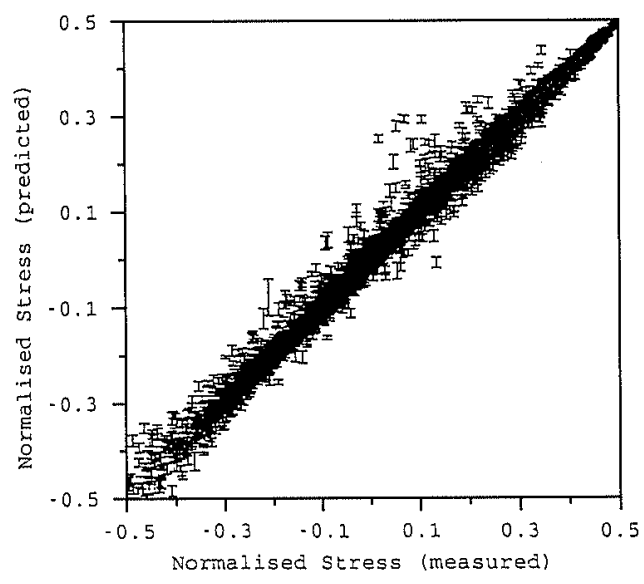

Fig. 6. The comparison of the measured stress with the neural network committee prediction, after retraining the committee using the whole database.

the form:

$$
L P E=\sum_{m} \frac{1}{2}\left(t^{m}-y^{m}\right)^{2} / \sigma_{y}^{m^{2}}+\log \left(\sqrt{2 \pi} \sigma_{y}^{m^{2}}\right)
$$

Having chosen a model which minimises the error in predicting the test data, the neural network corresponding to that model is retrained on the entire dataset.

\section{The Committee Model}

The predictions made by using a committee of models ${ }^{19)}$ can be more accurate than the single best model. Figures 2 and 3 present models that may be ranked ac- 


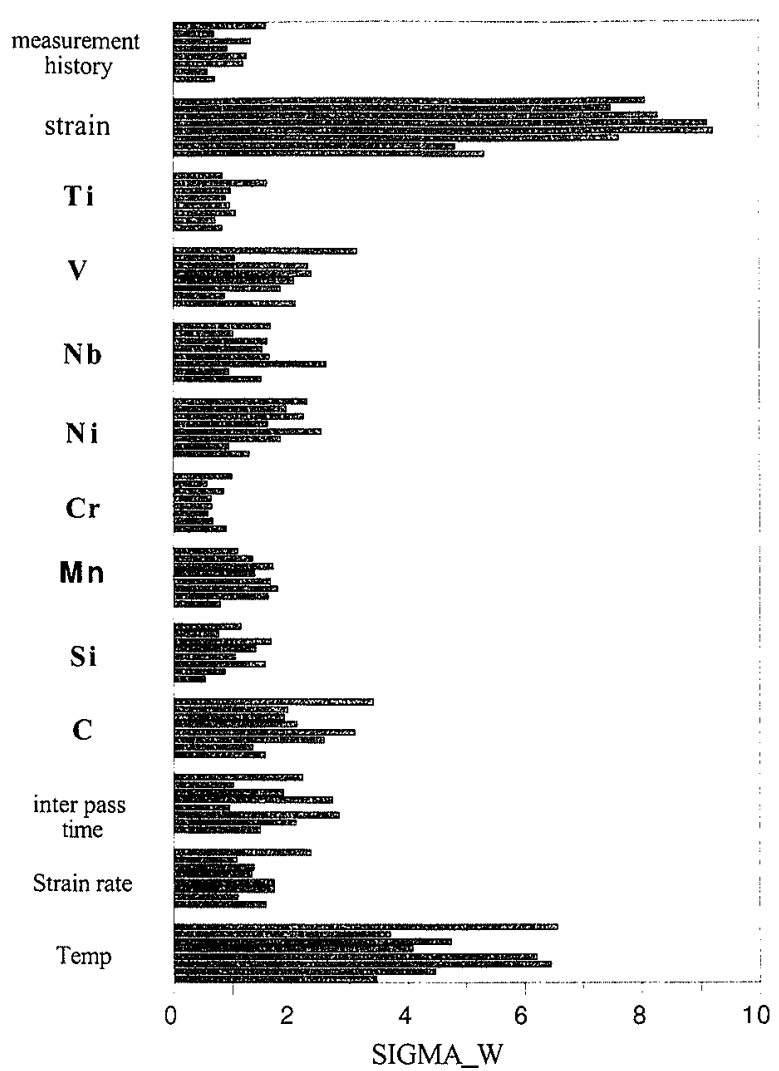

Fig. 7. The bar chart of the model perceived significance for each input used in the eight model "committee" to predict the stress. For each input, the bars (top to bottom) correspond to hidden units 20,20,19, 19,20, 20,19 and 19 where the seed of random number used to start the training was $40,1,20,30,20$, 30,10 and 40 respectively.

cording to the magnitude of the test error. We construct a committee however, by using $N$ models ranked by log predictive error, which is a measure of error that is less sensitive to outliers. The committee is formed through combining the best $N$ models (where $N=1,2,3, \cdots$ ) such that the mean prediction of the committee is:

$$
\bar{y}=\frac{1}{N} \sum_{i=1}^{N} y_{i}
$$

with the error in $\bar{y}$ expressed as:

$$
\sigma^{2}=\frac{1}{N} \sum_{i=1}^{N} \sigma_{v_{i}}^{2}+\frac{1}{N} \sum_{i=1}^{N}\left(y_{i}-\bar{y}\right)^{2}
$$

Figure 4 shows the test error as a function of the number of models used to form a committee. The figure shows that an eight model committee is the most favourable. In Fig. 5, committee predictions are compared against experimental data. The accuracy of the predictions improves after retraining as shown in Fig. 6.

\section{The Significance of Individual Inputs on the Stress Strain Curve}

Figure 7 illustrates the significance $\sigma_{w}$ of each of the inputs, as perceived by the neural network model. A large value of $\sigma_{w}$ implies that the input concerned explains a relatively large amount of the variation in the stress in
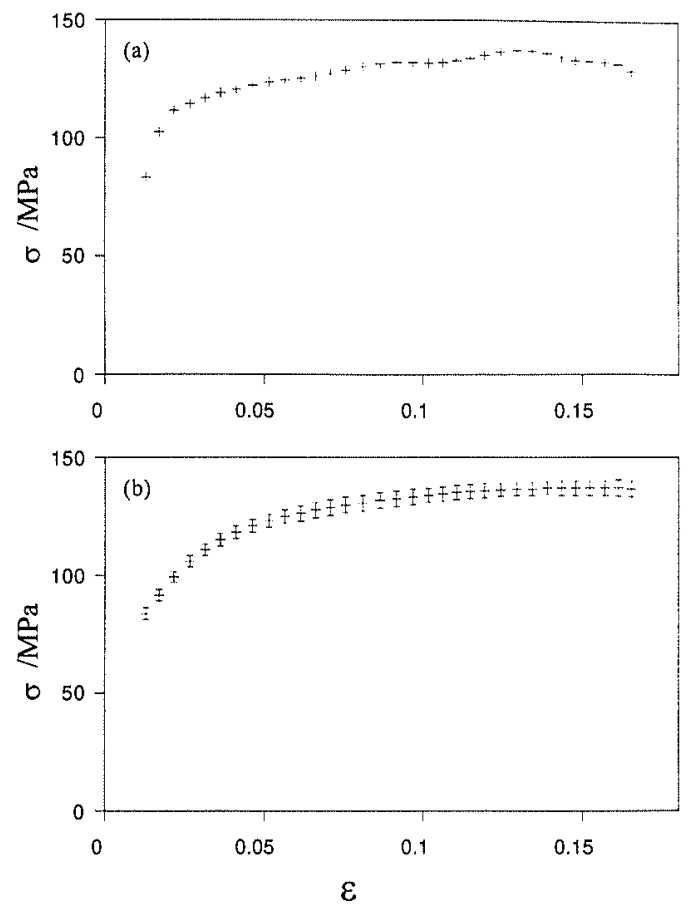

Fig. 8. The comparison of the stress-strain graph of alloy A measured by torsion experiments (a) with (b) the predicted graph for deformation at $950^{\circ} \mathrm{C}$. For strain rate $1.6 \mathrm{~s}^{-1}$ and interpass time $30 \mathrm{~s}$.
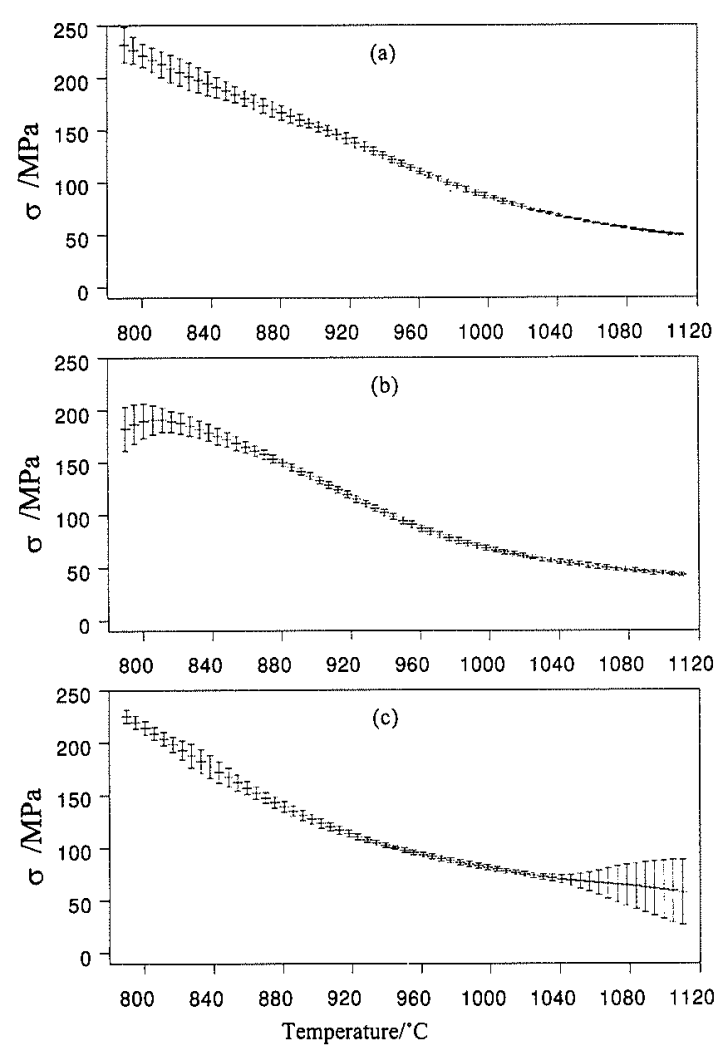

Fig. 9. The predicted stress at strain 0.04 as a function of temperature for alloys (a) A, (b) C and (c) F. For strain rate $1.0 \mathrm{~s}^{-1}$ and interpass time $30 \mathrm{~s}$.

the dataset (analogous to the partial correlation coefficient in the multiple regression technique). The $\sigma_{w}$ value is not however, an indication of the sensitivity of the stress to a particular input. For some inputs we observe a significant scatter of $\sigma_{w}$, indicating that the 


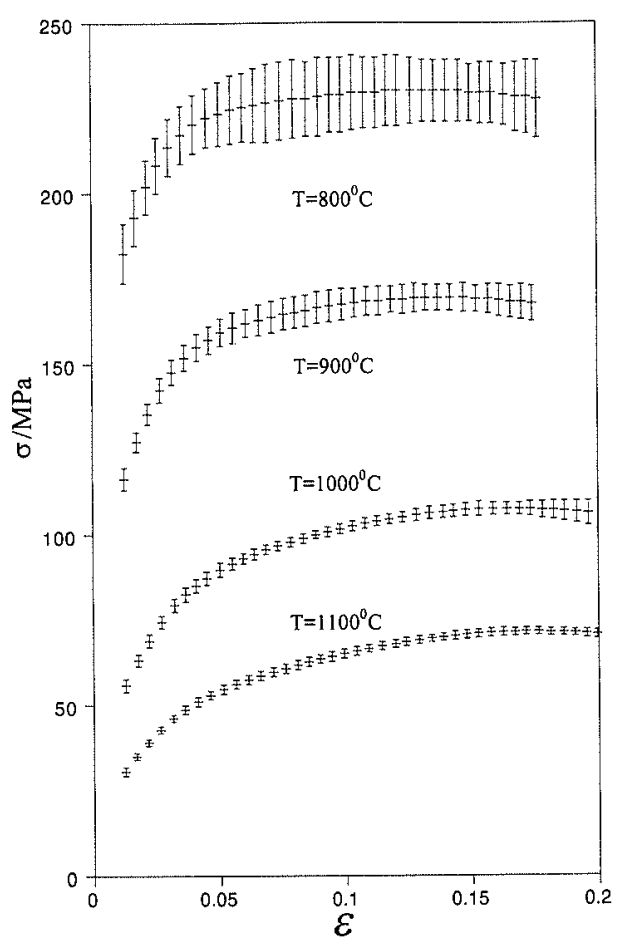

Fig. 10. The predicted stress strain graph of alloy $A$ for a range of temperatures. For strain rate $1.0 \mathrm{~s}^{-1}$ and interpass time $30 \mathrm{~s}$.

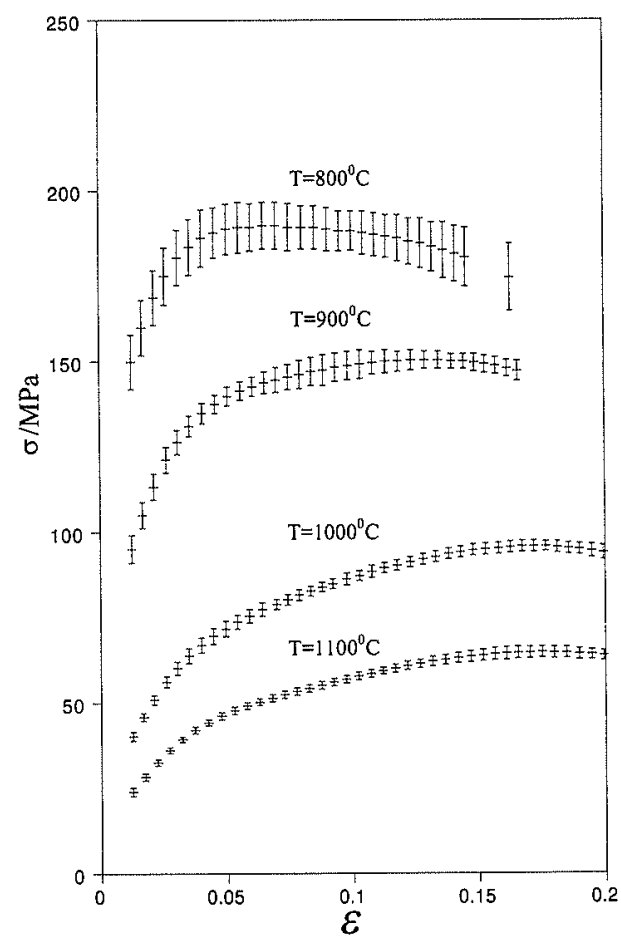

Fig. 11. The predicted stress strain graph of alloy $C$ for a range of temperatures. For strain rate $1.0 \mathrm{~s}^{-1}$ and interpass time $30 \mathrm{~s}$.

relationships identified for that input has a large uncertainty. The stress naturally is found to be sensitive to temperature and strain.

\section{Application of the Model}

We shall predict the stress-strain graphs for three typical steels: (i) A which has a small vanadium content
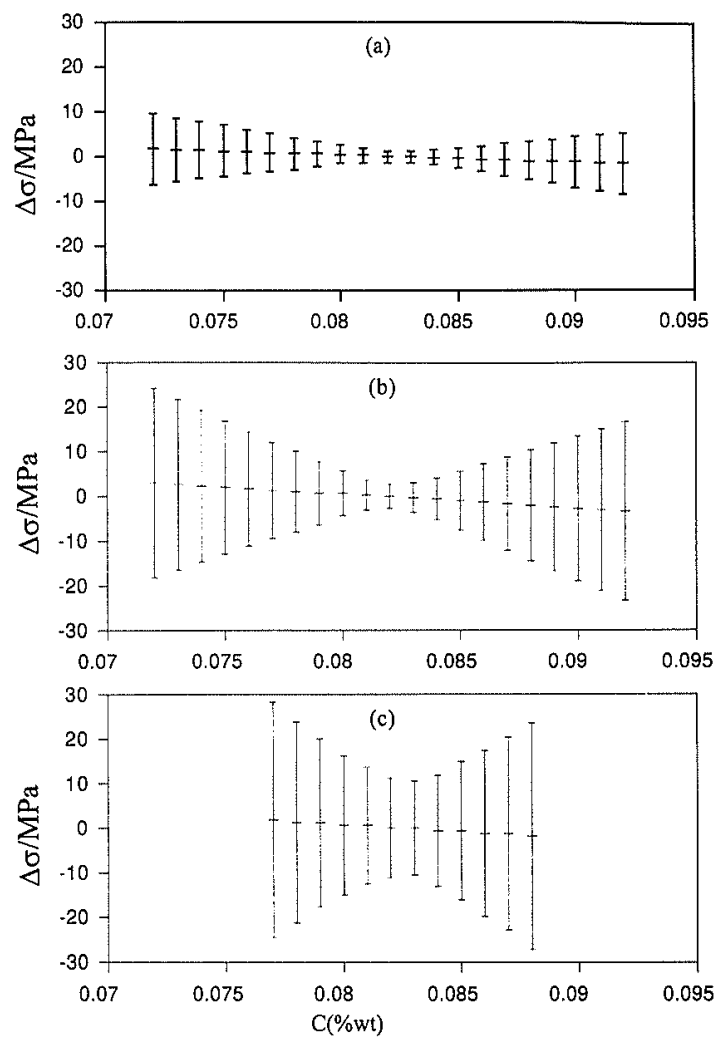

Fig. 12. The variation in measured stress (at strain 0.04 ) of $A$, as a function of carbon concentration, for temperatures (a) $1100^{\circ} \mathrm{C}$, (b) $950^{\circ} \mathrm{C}$ and (c) $800^{\circ} \mathrm{C}$.
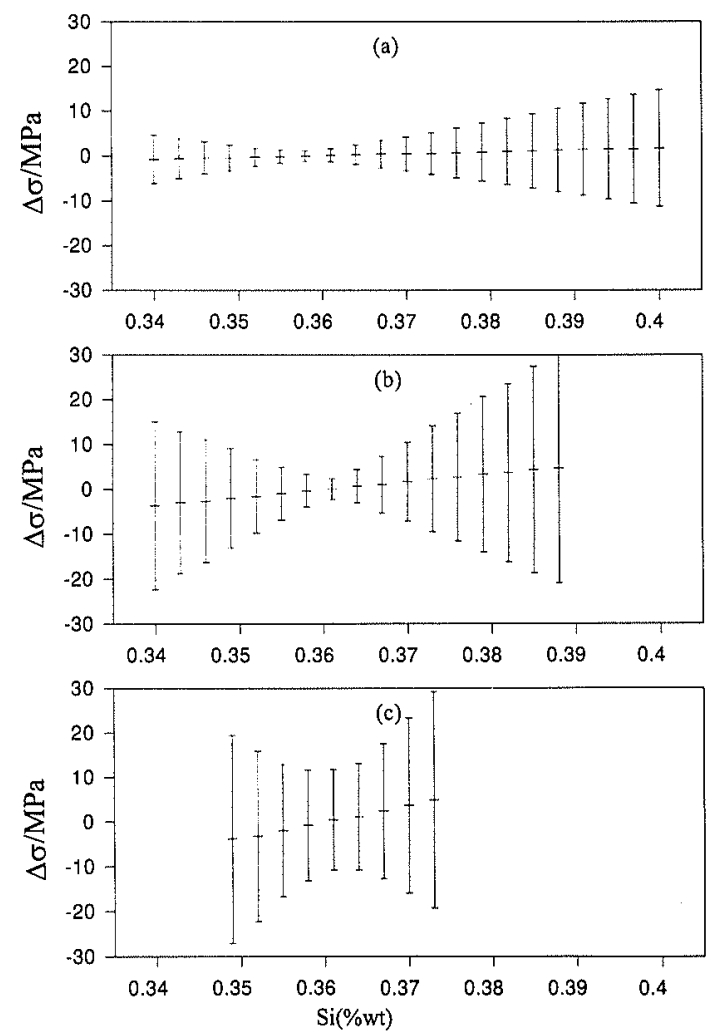

Fig. 13. The variation in measured stress (at strain 0.04 ) of $A$, as a function of silicon concentration, for temperatures (a) $1100^{\circ} \mathrm{C}$, (b) $950^{\circ} \mathrm{C}$ and (c) $800^{\circ} \mathrm{C}$.

(ii) $\mathrm{C}$ with carbon content $0.14(\% \mathrm{wt})$ and other elements in relatively small proportions and (iii) $\mathrm{E}$ which is a low carbon steel that contains small amounts of niobium. 

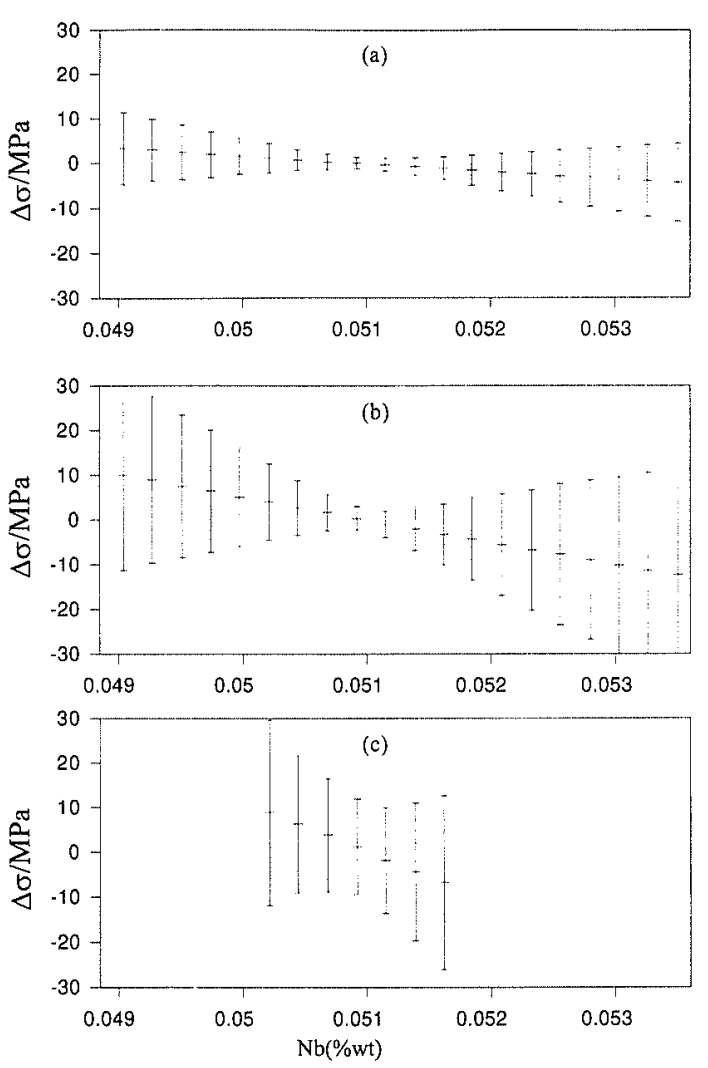

Fig. 14. The variation in measured stress (at strain 0.04) of $A$, as a function of carbon concentration, for temperatures (a) $1100^{\circ} \mathrm{C}$, (b) $950^{\circ} \mathrm{C}$ and (c) $800^{\circ} \mathrm{C}$.
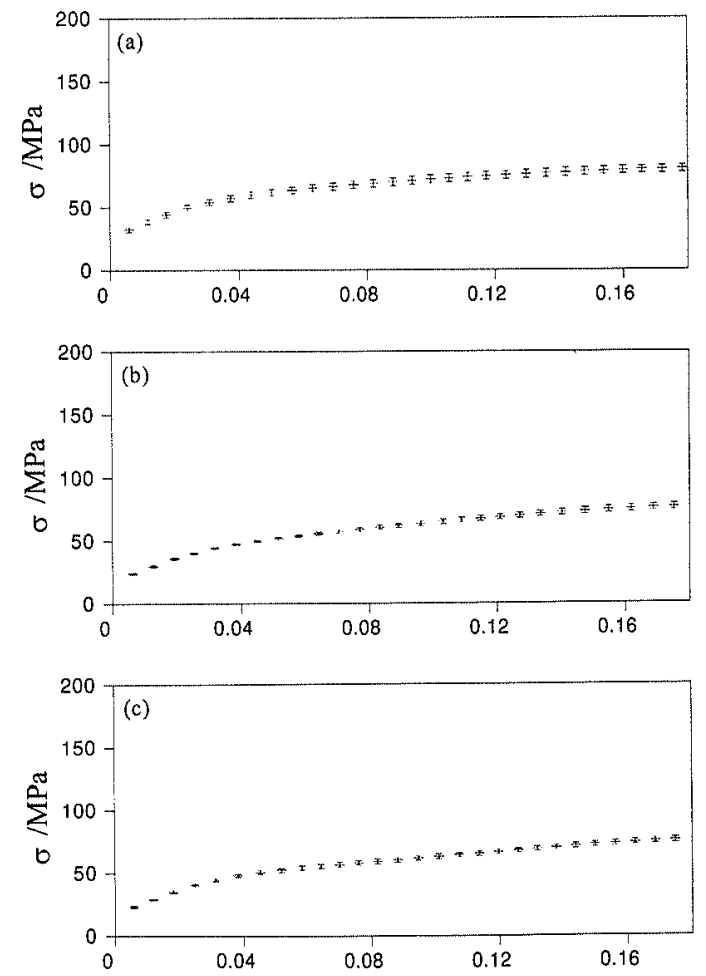

Fig. 15. The predicted stress strain graph of alloy $\mathrm{E}$ at $1100^{\circ} \mathrm{C}$ for interpass times (a) $5 \mathrm{~s}$, (b) $30 \mathrm{~s}$ and (c) $100 \mathrm{~s}$ for strain rate $1.6 \mathrm{~s}^{-1}$.

The input database, contains stress-strain measurements of $\mathrm{A}$ at fourteen different temperatures including $950^{\circ} \mathrm{C}$. In Fig. 8, the predicted stress-strain graph of alloy $\mathrm{A}$ at $950^{\circ} \mathrm{C}$, is compared with the measured graph, and there
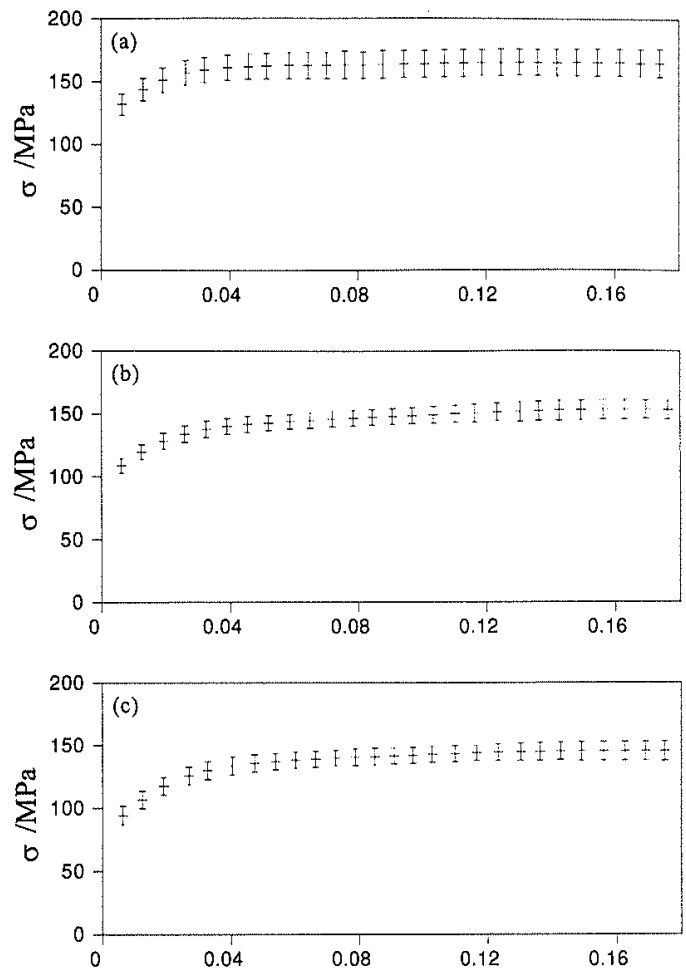

Fig. 16. The predicted stress strain graph of alloy $\mathrm{E}$ at $950^{\circ} \mathrm{C}$ for interpass times (a) $5 \mathrm{~s}$, (b) $30 \mathrm{~s}$ and (c) $100 \mathrm{~s}$ for strain rate $1.6 \mathrm{~s}^{-1}$.

is reasonable agreement.

In Fig. 9, we predict the stress at 0.04 strain as a function of temperature for alloys $\mathrm{A}, \mathrm{C}$ and $\mathrm{F}$ (that has a relatively high carbon content). Notice the predicted stress for these alloys, encompasses a narrower range with increasing temperature. Figures $\mathbf{1 0}$ and $\mathbf{1 1}$ show the stress-strain graphs for alloys $\mathrm{A}$ and $\mathrm{C}$ respectively, as a function of temperature. The results illustrate that the recovery mechanism, as seen in previous studies, ${ }^{20,21)}$ is highly temperature dependent. Comparing these figures, we note that at the temperature $1100^{\circ} \mathrm{C}$ the graphs for both alloys are very similar, thus the element variation between these alloys has little effect. At lower temperatures, the graphs become less similar and the difference in element concentration becomes more significant.

The variation of the stress at 0.04 strain of $\mathrm{A}$, as a function of some solutes is next predicted. In this study, a single element in $\mathrm{A}$ was chosen and its concentration was altered. The results are shown in Figs. 12, 13 and 14 at the temperatures $1100^{\circ} \mathrm{C}, 950^{\circ} \mathrm{C}$ and $800^{\circ} \mathrm{C}$. The predictions indicate, that changing the concentration of these elements does not dramatically effect the stress for these temperatures. The error bars however, are large with significant changes in element concentration (particularly at $800^{\circ} \mathrm{C}$ ), indicating that the neural network is not sure at these alloy configurations.

We next predict the stress-strain graph of alloy $E$ as a function interpass time at high and low temperatures. Figure 15 shows the predicted stress-strain graphs of $\mathrm{E}$ at $1100^{\circ} \mathrm{C}$ for interpass times 5,30 and $100 \mathrm{~s}$ with "strain history" $0.28,0.30$ and 0.29 respectively. Given that the "strain histories" at all interpass times are similar, the 
graphs clearly show that the stress-strain relation is virtually independent of interpass time. We may conclude therefore, that static recrystallisation, at this high temperature occurs very rapidly (faster than $5 \mathrm{~s}$ ).

Figure 16 shows the predicted stress-strain graphs of $\mathrm{E}$ at $950^{\circ} \mathrm{C}$ for interpass times 5,30 and $100 \mathrm{~s}$ with "strain history" $0.26,0.24$ and 0.24 respectively. These graphs show that the stress-strain graph is dependent on interpass time, since the "strain history" at all interpass times are similar. In this case we are in the range of low temperature, and recrystalisation of steel cannot occur, and the strain is accumulated from pass to pass, so that the stress increases not only due to the decrease in temperature but also due to strain hardening (stress levels of around $150 \mathrm{MPa}$ in Fig. 16 compared to $50 \mathrm{MPa}$ in Fig. 15, which corresponds to a higher temperature in the range of recrystalisation). The experiment measurements of $E$ indicates that for an interpass time of $5 \mathrm{~s}$, the minimum recrystallisation temperature is $1011^{\circ} \mathrm{C}$ and for interpass times $30 \mathrm{~s}$ and $100 \mathrm{~s}$ the minimum recrystallisation temperature is $985^{\circ} \mathrm{C}$ and $971^{\circ} \mathrm{C}$ respectively. This assumes that for the lower interpass times the amount of accumulated strain (given by the amount of strain applied below the recrystallisation temperature) is greater than for the longer interpass times. For these reasons we observe in Fig. 16, a higher stress level for interpass times of $5 \mathrm{~s}$ when compared to $30 \mathrm{~s}$ and $100 \mathrm{~s}$.

\section{Conclusions}

We have used a neural network model within a Bayesian framework to predict the stress-strain graph of a number of steels. A committee of neural network models which is found to be more accurate than using a single model and more reliable error bars. Reasonable predictions have been made for several steels, which agree with experimental measurements. The stress-strain graphs have been shown to be (i) highly dependent on temperature and (ii) less sensitive to the interpass time with increasing temperature (iii) not very sensitive to chemical composition at very high temperatures.

\section{REFERENCES}

1) C. M. Sellars and W. J. McG Tegart: Int Met. Rev., 17(1972), 1.

2) J. L. Nazabal, J. J. Urcola and M. Fuentes: Mater. Sci. Eng., 86 (1987), 93.

3) E. Ruibal, J. J. Urcola and M. Fuentes: Met. Technol., 11 (1982), 323.

4) C. Rossard and P. Blain: Mem. Sci. Rev. Metall., 56 (1959), 285.

5) D. Hardwick and W. J. McG Tegart: J. Inst. Met, 90 (1961), 17.

6) H. J. McQueen, W. A. Wong and J. J. Jonas: Can. J. Phys., 45 (1967), 1225.

7) I. Gutierrez, C. Francisco, J. J. Urcola and M. Fuentes: $Z$. Metallkd., 81 (1990), 136.

8) C. M. Sellars and W. J. McG Tegart: Int. Metall. Rev., 17 (1972), 1.

9) J. J. Jonas, C. M. Sellars and W. J. McG Tegart: Metall. Rev, 130 (1970).

10) Rossard and P. Blain: Mem. Sci. Rev. Met., 57 (1960), 173.

11) D. J. C. Mackay: Neural Computation, 4 (1992), 415.

12) D. J. C. Mackay: Neural Computation, 4 (1992), 448.

13) D. J. C. Mackay: Netual Computation, 4 (1992), 698.

14) T. Sakai: Hot Deformation and Fracture, ISIJ, Tokyo, (1981).

15) T. Sakai, M. G. Akben and J. J. Jonas: Thermomechanical Processing of Microalloyed Austenite, AIME, New York, (1982).

16) D. S. Fields and W. A. Backofen: Proc. ASTM, 57 (1957), 1259.

17) C. Rossard and P. Blain: Rev. Met., 55 (1958), 573.

18) D. J. C. MacKay: Networks Computation in Neural Systems, 6 (1995), 469.

19) S. Yoshitake, V. Narayan, H. K. D. B. Bhadenshia and D. J. MacKay: ISIJ Int., 38 (1998), 495.

20) C. Rossard and P. Blain: Mem. Sci. Rev. Met., 56 (1959), 286.

21) A. T. English and W. A. Backofen: Trans, Metall. Soc. AIME, 212 (1964), 396 